\title{
Post-combustion $\mathrm{CO}_{2}$ capture with a commercial activated carbon: comparison of different regeneration strategies
}

\author{
M.G. Plaza, S. García, F. Rubiera, J.J. Pis, C. Pevida* \\ Instituto Nacional del Carbón, CSIC, Apartado 73, 33080 Oviedo, Spain
}

\begin{abstract}
A commercial activated carbon supplied by Norit, R2030CO2, was evaluated as $\mathrm{CO}_{2}$ adsorbent under conditions relevant to post-combustion $\mathrm{CO}_{2}$ capture (ambient pressure and diluted $\mathrm{CO}_{2}$ ). It has been demonstrated that this carbon possesses sufficient $\mathrm{CO}_{2} / \mathrm{N}_{2}$ selectivity in order to efficiently separate a binary mixture composed of $17 \% \mathrm{CO}_{2}$ in $\mathrm{N}_{2}$. Moreover, this carbon was easily completely regenerated and it did not show capacity decay after ten consecutive cycles. Three different regeneration strategies were compared in a single-bed adsorption unit: temperature swing adsorption (TSA), vacuum swing adsorption (VSA) and a combination of them, vacuum and temperature swing adsorption (VTSA). Through a simple two step TSA cycle, $\mathrm{CO}_{2}$ was concentrated from 17 to $43 \%$ (vol). For the single-bed cycle configurations, the productivity and $\mathrm{CO}_{2}$ recovery followed the sequence: TSA $<$ VSA $<$ VTSA. Values of productivity up to $1.9 \mathrm{~mol} \mathrm{~kg}^{-1} \mathrm{~h}^{-1}$ and a maximum $\mathrm{CO}_{2}$ recovery of $97 \%$ were reached.
\end{abstract}

Keywords: $\mathrm{CO}_{2}$ capture, adsorption cycles, activated carbon.

\footnotetext{
* Corresponding author. Tel.: +34 9851189 87: Fax: +34 985297662

e-mail address: cpevida@incar.csic.es (C. Pevida)
} 


\section{Introduction}

Due to the strong dependence on fossil fuels within the current energy scenario, Carbon Capture and Storage (CCS) will play a crucial role to attain the required greenhouse gas (GHG) emissions reduction, in order to avoid permanent and irreversible damage to the climate system. The International Energy Agency (IEA) claims that CCS could bring $19 \%$ of energy related $\mathrm{CO}_{2}$ emissions mitigation effort by 2050 [1]. Without CCS technologies, the stabilization cost could increase up to $70 \%$ [2].

Chemical absorption with amines is currently used to carry out $\mathrm{CO}_{2}$ separation in industrial processes such as the sweetening of natural gas, and hydrogen or ammonia production. It is regarded as the most ready-to-use technology for post-combustion $\mathrm{CO}_{2}$ capture. However, this technology presents a series of drawbacks, such as high energy requirement associated to sorbent regeneration, amine losses due to evaporation, corrosion problems, thermal and chemical degradation of the amines in the presence of oxygen, etc. Adsorption is a separation technology with potential to reduce the cost of post-combustion capture compared to amine scrubbing [3-5]. Two main adsorption technologies are being considered: pressure swing adsorption (PSA) and temperature swing adsorption (TSA). The difference between both technologies lies in the strategy to regenerate the adsorbent after the adsorption step. In PSA applications, the pressure of the bed is reduced, whereas in TSA, the temperature is raised while pressure is maintained approximately constant. Usually, the term vacuum swing adsorption (VSA) is preferred to refer to the special PSA application where the desorption pressure is below atmospheric. Within TSA technologies, the specific case in which the solid is heated by the Joule effect is commonly referred to as electric swing adsorption (ESA) $[5,6]$. The vast majority of studies dealing with $\mathrm{CO}_{2}$ post-combustion capture by means of PSA or TSA technologies use zeolites as adsorbent [6-20]. Zeolite 13X is by far the adsorbent most extensively studied in $\mathrm{CO}_{2}$ separation processes, due to its high selectivity to $\mathrm{CO}_{2}$ [21]. However, several studies have also appeared in the literature dealing with activated carbons [4, 22]. Activated carbons present important advantages over zeolites, such as hydrophobicity, significant lower cost, and lower energy requirements to carry out their regeneration (the isosteric heat of adsorption of $\mathrm{CO}_{2}$ over activated carbons is $c a .20 \mathrm{~kJ} \mathrm{~mol}^{-1}$ [23], which is nearly half of that of zeolite $13 \mathrm{X}$ [21, 24]). Ho et al. estimated that using zeolite $13 \mathrm{X}$, a capture cost of US\$ 51 per ton of $\mathrm{CO}_{2}$ avoided could be attained, including the cost of product compression (purity of $48 \%$ ), 
with an additional capital investment for capture of US\$ 1300 per kW [3]. Radosz et al. estimated a total cost of compressed-pipeline ready $\mathrm{CO}_{2}$ of US\$ 27 per ton for a power plant integrated TSA process, and of US\$ 44 per ton for a VSA process, using an activated carbon as adsorbent [4].

Previous research in our group dealt with the production of effective $\mathrm{CO}_{2}$ adsorbents from a wide range of carbon-based precursors. Besides a suitable textural development, particular attention has been paid to the incorporation of basic nitrogen functionalities to enhance the affinity of the adsorbents towards $\mathrm{CO}_{2}$ [25-30].

In this work the potential of activated carbons to separate $\mathrm{CO}_{2}$ from $\mathrm{N}_{2} / \mathrm{CO}_{2}$ mixtures has been evaluated. For this purpose, a commercial activated carbon was selected. Firstly, the selectivity of the activated carbon to separate $\mathrm{CO}_{2}$ from $\mathrm{CO}_{2} / \mathrm{N}_{2}$ streams has been assessed from the $\mathrm{CO}_{2}$ and $\mathrm{N}_{2}$ adsorption isotherms and, secondly, the performance of this carbon to capture $\mathrm{CO}_{2}$ from a $\mathrm{N}_{2} / \mathrm{CO}_{2}$ binary mixture, representative of a flue gas, has been evaluated from the corresponding breakthrough curves. Finally, different strategies to conduct the regeneration step in a cyclic adsorption-desorption process treating a simulated flue gas have been compared.

\section{Materials and methods}

The commercial activated carbon used in this work is a steam activated peat-based extruded carbon kindly provided by Norit (Norit R2030 CO2). It will be denoted from now on as R. A detailed textural characterisation of $\mathrm{R}$ can be found elsewhere [27].

Single-component $\mathrm{N}_{2}$ and $\mathrm{CO}_{2}$ adsorption isotherms were determined at $303 \mathrm{~K}$ in a volumetric apparatus, Micromeritics TriStar 3000, from $0.054 \mathrm{~Pa}$ up to $113.25 \mathrm{kPa}$. Prior to these adsorption measurements, the samples were outgassed overnight at $373 \mathrm{~K}$ under vacuum.

Multi-component gas adsorption experiments were carried out in a purpose-built fixed-bed adsorption unit, schematized in Figure 1. Individual gas flowrates of $\mathrm{N}_{2}$ and $\mathrm{CO}_{2}$ were set by means of accurate mass flow controllers from Bronkhorst High-Tech, and subsequently mixed in a helicoidal distributor that assures perfect mixing of the feed gas before entering the bed. The fixed-bed consists of a stainless steel reactor of $9 \mathrm{~mm}$ diameter and $203 \mathrm{~mm}$ height, with a porous plate located at $46 \mathrm{~mm}$ from the bottom of the column. The temperature of the solids bed was monitored continuously by means of a K-type thermocouple placed inside the solids bed at $45 \mathrm{~mm}$ from the porous plate. It was controlled by coupling a heating element coiled around the reactor to an 
air-cooling device. The bed pressure was controlled by means of a back-pressure regulator located in the outlet pipe. The composition of the outlet gas stream was measured by a dual channel micro-gas chromatograph (micro-GC), CP 4900 from Varian, fitted with a thermal conductive detector (TCD) and using He as the carrier gas. The TCD response was calibrated using standards of $\mathrm{CO}_{2}-\mathrm{N}_{2}$ mixtures of known compositions. Table 1 sumarises the physical properties of the adsorbent and the bed characteristics.

The term breakthrough curve refers to the response of an initially free of adsorbate bed to an influent of constant or variable composition. In this work, the solids bed was regenerated prior to each breakthrough test by heating the solids up to $373 \mathrm{~K}$ for $1 \mathrm{~h}$ while purging with $10 \mathrm{~cm}^{3} \mathrm{~min}^{-1} \mathrm{STP}$ of $\mathrm{N}_{2}$. Then, the initially $\mathrm{CO}_{2}$-free bed (full of $\mathrm{N}_{2}$ ) was first fed with the desired flow of $\mathrm{N}_{2}$, and, after $5 \mathrm{~min}$, the selected $\mathrm{CO}_{2}$ flow was added to the feed stream keeping the flowrate of $\mathrm{N}_{2}$. Table 2 presents the operating conditions selected for the breakthrough experiments carried out in this work.

The quantity of $\mathrm{CO}_{2}$ adsorbed on the carbon can be determined from the breakthrough experiments by applying a mass balance to the bed, as illustrated in Equation 1. Note that the $\mathrm{CO}_{2}$ stored in the bed voidage must be substracted from the total quantity of $\mathrm{CO}_{2}$ accumulated in the bed to calculate the actual $\mathrm{CO}_{2}$ adsorbed on the carbon.

$q_{\mathrm{CO}_{2}}=\frac{1}{m_{\text {adsorbent }}}\left[\int_{0}^{t_{\mathrm{s}}}\left(F_{\mathrm{CO}_{2}, \text { in }}-F_{\mathrm{CO}_{2}, \text { out }}\right) d t-\frac{y_{\mathrm{CO}_{2}, \text { feed }} P \varepsilon_{T} V_{b}}{R T}\right]$

In Equation 1, $q_{\mathrm{CO}_{2}}$ stands for the specific $\mathrm{CO}_{2}$ adsorption capacity of the adsorbent, $m_{\text {adsorbent }}$ is the mass of adsorbent in the bed, $F_{\mathrm{CO}_{2}, \text { in }}$ and $F_{\mathrm{CO}_{2} \text {,out }}$ refer to the molar flowrate of $\mathrm{CO}_{2}$ at the inlet and outlet of the bed, respectively, $t_{s}$ refers to the time to reach saturation, $y_{\mathrm{CO}_{2}, \text { feed }}$ is the molar fraction of $\mathrm{CO}_{2}$ in the feed stream, $P$ and $T$ are the pressure and temperature of bed at equilibrium, $\varepsilon_{T}$ is the total porosity of the bed, $V_{b}$ is the bed volume and $R$ is the universal gas constant. The concentration of $\mathrm{CO}_{2}$ in the flow at any given point in the bed is a function of time, resulting from the movement of the concentration front in the bed. Konduru et al. [20] proposed a graphical method to calculate the first term of Equation 1 from the ratio of the adsorbed area $\left(A_{t}\right)$ on the total area $\left(A_{t o t}\right)$ of the $\mathrm{CO}_{2}$ breakthrough curve, according to the following equation:

$m_{A}=A_{t} / A_{\text {tot }} \times m_{\text {tot }}$ 
where $m_{A}$ is the mass of $\mathrm{CO}_{2}$ adsorbed; $A_{t}$ is the area $(\% \mathrm{v} / \mathrm{v} \min )$ above the breakthrough curve at time $t ; A_{\text {tot }}$ is the total area $(\% \mathrm{v} / \mathrm{v} \mathrm{min})$ at time $t$ and $m_{\text {tot }}$ is the total mass of $\mathrm{CO}_{2}$ that has entered the system at time $t$. The latter one can be computed from the inlet molar flowrate of $\mathrm{CO}_{2}\left(\mathrm{~mol} \mathrm{~min}^{-1}\right)$, the duration time of the cycle (min) and the $\mathrm{CO}_{2}$ molecular weight $\left(\mathrm{g} \mathrm{mol}^{-1}\right)$. Figure 2 illustrates the graphical method used to estimate the capture ratio $A_{t} / A_{\text {tot }}$. The second term in Equation 1 was computed and can be considered negligible under the studied conditions.

Finally, three strategies to regenerate the solids bed were considered. Cyclic adsorption-desorption experiments were carried out simulating temperature swing adsorption (TSA), vacuum swing adsorption (VSA), and a combination of vacuum and temperature swing adsorption (VTSA) processes. The cycle time was set to simulate operation with two beds, with equal duration of the adsorption and desorption steps. For comparison purposes, cycle time $(14 \mathrm{~min})$, feed flowrate $\left(34 \mathrm{~cm}^{3} \mathrm{~min}^{-1} \mathrm{STP}\right)$, feed composition (17\% $\mathrm{CO}_{2}$ in $\mathrm{N}_{2}$ ) and adsorption operating conditions, temperature $(303 \mathrm{~K})$ and pressure $(130 \mathrm{kPa})$, were maintained for the three cycle configurations. An adsorption time of $7 \mathrm{~min}$, lower than the breakthrough time under the aforementioned conditions (see Figure 5c), was selected. Therefore, the TSA, VSA and VTSA experiments will differ in the operating conditions of the regeneration step:

- In the TSA cycles, regeneration of the adsorbent was conducted by raising the temperature of the bed up to $373 \mathrm{~K}$ while feeding a small purge of nitrogen $\left(2.6 \mathrm{~cm}^{3} \mathrm{~min}^{-1} \mathrm{STP}\right)$ and keeping the pressure bed constant $(130 \mathrm{kPa})$.

- During the desorption step of the VSA cycles, the bed inlet is closed and the bed outlet is conected to a vacuum pump. Then, the bed is evacuated down to a final pressure of $5 \mathrm{~Pa}$ at a constant temperature of $303 \mathrm{~K}$. Vacuum was accurately controlled by a vacuum controller, Center One from Oerlikon Leybold vacuum, coupled to a Thermovac pressure transducer that actionated an electrovalve linked to the vacuum pump.

- In the VTSA cycles, the regeneration step also involved the evacuation of the bed down to $5 \mathrm{~Pa}$ with the bed inlet closed, although in this case the temperature of the bed was simultaneously raised up to $323 \mathrm{~K}$.

\section{Results and discussion}

\subsection{Equilibrium adsorption isotherms of pure components}


The single-component $\mathrm{CO}_{2}$ and $\mathrm{N}_{2}$ adsorption isotherms at $303 \mathrm{~K}$ for activated carbon $\mathrm{R}$ are shown in Figure 3a. $\mathrm{R}$ presents low nitrogen adsorption capacity and a linear isotherm that indicates weak adsorption forces. On the other hand, $\mathrm{R}$ presents a significantly higher $\mathrm{CO}_{2}$ adsorption capacity with a curve-shaped isotherm (favorable equilibrium isotherm).

The adsorbent selectivity to $\mathrm{CO}_{2}$ over $\mathrm{N}_{2}$ can be assessed by dividing the adsorption capacity of $\mathrm{CO}_{2}$ by that of $\mathrm{N}_{2}$ at a given pressure [21,31]. This "ideal selectivity" displays an asymptotic behaviour with increasing pressure showing a sharp drop in the low-pressure range $(\mathrm{P}<10 \mathrm{kPa})$, and approaching a near constant value shortly after (Figure $3 \mathrm{~b}$ ). The amount of $\mathrm{CO}_{2}$ adsorbed at atmospheric pressure and $303 \mathrm{~K}$ is approximately seven times that of $\mathrm{N}_{2}$.

Figure 4 presents the $\mathrm{CO}_{2}$ adsorption isotherms at $298 \mathrm{~K}$ up to $3 \mathrm{MPa}$ for zeolite $13 \mathrm{X}$ [21] and carbon R. It can be observed that R presents a significantly less pronounced curvature compared to zeolite-type materials, thus showing higher potential for regeneration by lowering the pressure.

\subsection{Breakthrough experiments with $\mathrm{CO}_{2} / \mathrm{N}_{2}$ binary mixtures}

Figures 5 and 6 show the breakthrough curves obtained for the activated carbon $\mathrm{R}$ under different operating conditions (see Table 2). After initial regeneration of the adsorbent, a feed mixture with a constant $\mathrm{CO}_{2}$ concentration is fed into the bed. The response to the step perturbation in the feed composition involves a mass transfer zone which propagates through the column at a velocity determined by the equilibrium $[32,33]$. The heat and mass transfer resistances within the bed and the particles have only a dispersive effect on the shape of the wavefront.

Figure 5 shows in detail the breakthrough experiment conducted under Case 1 (303 K, $130 \mathrm{kPa}, 34 \mathrm{~cm}^{3} \mathrm{~min}^{-1} \mathrm{STP}, 17 \% \mathrm{CO}_{2}$ ) operating conditions. The complete experiment consisted of ten consecutive cycles where the adsorbent reached saturation during the adsorption step and was completely regerenerated during the desorption step (see Figure 5a). Regeneration was conducted raising the temperature of the bed up to $373 \mathrm{~K}$ while purging with $10 \mathrm{~cm}^{3} \mathrm{~min}^{-1} \mathrm{STP}$ of $\mathrm{N}_{2}$. Figure $5 \mathrm{~b}$ presents the evolution of the $\mathrm{CO}_{2}$ mole fraction at the outlet of the bed during one adsorption-desorption cycle. It can be observed that while $\mathrm{CO}_{2}$ is being adsorbed on the carbon, during the adsorption step, it is not detected at the outlet of the bed and only when the breakthrough time is reached $\mathrm{CO}_{2}$ is detected in the outlet gas stream. The $\mathrm{CO}_{2}$ adsorption front reaches the outlet of 
the bed after $8 \mathrm{~min}$. Saturation of the bed $\left(y_{\mathrm{CO}_{2}, \text { out }}=y_{\mathrm{CO}_{2}, \text { feed }}\right)$ is achieved shortly after ( $\sim 17 \mathrm{~min})$. The raise in temperature results in a sharp $\mathrm{CO}_{2}$ peak at the beginning of the regeneration step. This peak presents two main contributions; one from the $\mathrm{CO}_{2}$ adsorbed on the carbon and another one from the $\mathrm{CO}_{2}$ that remains in the bed voidage at the end of the adsorption step. Complete regeneration of the adsorbent bed is achieved in approximately $30 \mathrm{~min}$. It should be mentioned that this $\mathrm{CO}_{2}$ desorption profile shows a significantly less dispersive character than that of zeolite-type materials [19], due to the easier regeneration of activated carbons.

Repeatability of the breakthrough experiments is shown in Figure 5 for Case 1 (Table 2). As can be seen in Figure 5c, consecutive breakthrough curves practically overlap. The larger difference was found in the first cycle, probably due to a slightly different initial condition of the solids bed.

The average $\mathrm{CO}_{2}$ capture capacity assessed from these breakthrough experiments (Case 1 in Table 2), $0.77 \mathrm{~mol} \mathrm{~kg}^{-1}$, is slightly below the maximum value predicted from the pure $\mathrm{CO}_{2}$ adsorption isotherm (Figure 3). This may be due to small $\mathrm{N}_{2}$ co-adsorption.

Series of breakthrough tests were carried out at a pressure of $120 \mathrm{kPa}$ and using a feed flowrate of $100 \mathrm{~cm}^{3} \mathrm{~min}^{-1} \mathrm{STP}$. Two temperatures were studied, 303 and $313 \mathrm{~K}$, at three different $\mathrm{CO}_{2}$ inlet concentrations, 5, 9 and $14 \%$ (Figure 6). The experimental conditions used and the resulting capture capacities are summarised in Table 2 (Cases 2-7). As expected, the $\mathrm{CO}_{2}$ capture capacity of the adsorbent at a certain temperature increases with $\mathrm{CO}_{2}$ partial pressure. However, as the temperature of the bed increases for a given $\mathrm{CO}_{2}$ partial pressure, the $\mathrm{CO}_{2}$ adsorption capacity of the adsorbent diminishes. For instance, it moves from $0.41 \mathrm{~mol} \mathrm{~kg}^{-1}$ at $303 \mathrm{~K}$ (Case 3) down to $0.33 \mathrm{~mol} \mathrm{~kg}^{-1}$ at $313 \mathrm{~K}$ (Case 6).

It can also be observed in Figure 6 that the shape of the breakthrough curves and the breakthrough times vary with temperature and $\mathrm{CO}_{2}$ partial pressure. Lower $\mathrm{CO}_{2}$ partial pressures result in longer breakthrough times due to the $\mathrm{CO}_{2}$ concentration front taking more time to reach the outlet of the bed. On the other hand, an increase in temperature favours mass transfer along the bed and thus increases the slope of the breakthrough curve.

\subsection{Cyclic adsorption experiments with $\mathrm{CO}_{2} / \mathrm{N}_{2}$ binary mixtures}


TSA, VSA and VTSA experiments differred in the operating conditions selected for the regeneration step. Thus, the extent of regeneration, during the desorption step, and the initial state of the bed, at the beginning of the next adsorption step, were affected. Table 3 summarises the operating conditions of the TSA, VSA and VTSA experiments conducted in this work.

In TSA experiments, a raise in temperature is used to regenerate the adsorbent. The most convenient way of raising the temperature is by purging the bed with a preheated gas. This usually results in longer cycle times because heating is slow and often ratelimiting step. However, in our particular case, the fixed-bed adsorption unit has been designed to conduct rapid heating and cooling of the bed. This allows shorter TSA cycle length with equal adsorption and desorption times. After regeneration, the bed needs to be cooled down to the adsorption temperature. In our case, cooling was carried out simultaneously to the adsorption step. This implied that the feed met an initially hot bed (at $373 \mathrm{~K}$ ), which was progresively cooled during the adsorption step, reaching $303 \mathrm{~K}$ only at the end of the adsorption step (see Figure 7). Although this configuration allowed to shorten the cycle length, it reduced the working capacity of the adsorbent to $0.19 \mathrm{~mol} \mathrm{~kg}^{-1}$. The $\mathrm{CO}_{2}$ recovery of the present cycle configuration is only $40 \%$ (see Table 3). It is worth to note that increasing the cycle length could result in a significant enhancement of the recovery and the working capacity, as illustrated by Case 1 in Table 2, where the adsorption capacity reached $0.77 \mathrm{~mol} \mathrm{~kg}^{-1}$ due to a deep regeneration of the bed. Nevertheless, cycle productivity, defined as the working capacity divided by the cycle time is negatively affected by any increase in cycle length. It is widely known that the main drawback of TSA cycles is $\mathrm{CO}_{2}$ dilution by the hot inert purge. Even so, with the simple aforementioned configuration, $\mathrm{CO}_{2}$ was concentrated from 17 to $43 \%$ (in volume). $\mathrm{CO}_{2}$ purity could be further increased by modifiying the original cycle, adding a purge step with part of the $\mathrm{CO}_{2}$ product [8]. However, it must be beared in mind that using part of the product to increase purity has a negative effect over productivity. Other alternatives include the use of low-pressure steam from the power station, heating by Joule effect (ESA) [6] or indirect heating [12]. Furthermore, even with an optimised TSA cycle, it would be necessary to feed the concentrated $\mathrm{CO}_{2}$ stream to a second unit to meet $\mathrm{CO}_{2}$ storage specifications $[34,35]$. The reduction in the flow rate and the increase of $\mathrm{CO}_{2}$ partial pressure may facilitate the separation process in the second unit. 
VSA cycles elude $\mathrm{CO}_{2}$ dilution, as inert purge is not necessary during the regeneration step. On the other hand, mechanical energy is generally more expensive than low-grade heat. Therefore, the final level of vacuum selected in a real VSA capture process will need to be carefully assesed, as this will drive the operating cost of the process. More than $70 \%$ of the power consumed in a VSA process is due to the vacuum pump [10]. The effect of the level of vacuum over the process parameters depends strongly on the shape of isotherm. Thus, the energy requirements could be lowered for an activated carbon compared to a zeolite-type adsorbent. With the VSA configuration studied in the present case (Figure 8), a working capacity of $0.39 \mathrm{~mol} \mathrm{~kg}^{-1}$ was attained, which is almost twice that achieved in the TSA configuration. Moreover, the $\mathrm{CO}_{2}$ recovery significantly increased up to $87 \%$ (see Table 3 ).

VTSA cycles combine the benefits of temperature and pressure as regeneration strategies. A slight increase in temperature may reduce the level of vacuum required to regenerate the bed, and thus the power costs. On the other hand, shorter cycle length is feasible due to small changes in the bed temperature. In the present case, and for comparative purposes, the desorption pressure has been maintained equal to the VSA case, but the temperature of the bed has been slightly increased up to $323 \mathrm{~K}$ during the regeneration step (Figure 9). Using this configuration, the productivity and $\mathrm{CO}_{2}$ recovery increased even beyond the VSA case reaching values up to $1.9 \mathrm{~mol} \mathrm{~kg}^{-1}$ and $97 \%$ (see Table 3), respectively, due to a deeper regeneration of the adsorbent.

Figure 10 shows the evolution of the working capacity of the adsorbent bed for the different cycle configurations, TSA, VSA and VTSA. It can be observed that in all cases the working capacity remains virtually constant along the cyclic experiment. This indicates the good cyclability and durability of the adsorbent as it does not lose capacity over consecutive adsorption-desorption cycles. Work is currently being developed to optimise cycle configurations by means of a purpose-built two-bed adsorption unit.

\section{Conclusions}

In this work, a commercial activated carbon has been tested as $\mathrm{CO}_{2}$ adsorbent under post-combustion conditions. This material presented adequate $\mathrm{CO}_{2} / \mathrm{N}_{2}$ selectivity and reversible adsorption. Moreover, it showed very good cyclability and durability over 10 consecutive adsorption-desorption cycles. Through a simple two step TSA cycle, $\mathrm{CO}_{2}$ was concentrated from 17 to $43 \%$ (vol). For the cycle configurations tested in the 
present work, the productivity and $\mathrm{CO}_{2}$ recovery followed the sequence VTSA $>$ VSA $>$ TSA. A productivity of $1.9 \mathrm{~mol} \mathrm{~kg}^{-1} \mathrm{~h}^{-1}$ with a $\mathrm{CO}_{2}$ recovery up to $97 \%$ were attained under VTSA operation. Although cycle configurations were not optimised, it can be concluded that carbon $\mathrm{R}$ shows promising performance as $\mathrm{CO}_{2}$ adsorbent for post-combustion capture applications, attending to its ease of regeneration and good cyclability. Further testing will be performed to optimise the three different regeneration strategies discussed herein (TSA, VSA and VTSA); likewise, a cost estimation of the involved regeneration energy for each strategy is needed to reallistically compare the $\mathrm{CO}_{2}$ capture potential of the activated carbon presented here with current state-of-the-art $\mathrm{CO}_{2}$ capture technologies.

\section{Notation}

$\begin{array}{ll}F_{\mathrm{CO}_{2}, \text { in }} & \text { molar flowrate of } \mathrm{CO}_{2} \text { at the inlet of the bed, } \mathrm{mol} \mathrm{s}^{-1} \\ F_{\mathrm{CO}_{2}, \text { out }} & \text { molar flowrate of } \mathrm{CO}_{2} \text { at the outlet of the bed, } \mathrm{mol} \mathrm{s}^{-1} \\ H & \text { heat, } \mathrm{kJ} \\ m_{\text {adsorbent }} & \text { mass of adsorbent present in the fixed bed, } \mathrm{kg} \\ P & \text { pressure, } \mathrm{kPa} \\ P_{\text {ads }} & \text { adsorption pressure, } \mathrm{kPa} \\ P_{\text {des }} & \text { desorption pressure, } \mathrm{kPa} \\ Q & \text { volumetric flowrate, } \mathrm{cm}{ }^{3} \mathrm{~min}^{-1}(\mathrm{STP}) \\ q_{C O_{2}} & \text { specific } \mathrm{CO}{ }_{2} \text { adsorption capacity of the adsorbent, } \mathrm{mol} \mathrm{kg}^{-1} \\ R & \text { universal gas constant, } 8.314 \mathrm{~J} \mathrm{~K}^{-1} \mathrm{~mol}^{-1} \\ T & \text { temperature, } \mathrm{K} \\ T_{a d s} & \text { adsorption temperature, } \mathrm{K} \\ T_{\text {des }} & \text { desorption temperature, } \mathrm{K} \\ t_{s} & \text { time to reach saturation, } \mathrm{s} \\ t_{c} & \text { cycle time, min }\end{array}$


$V_{b} \quad$ bed volume, $\mathrm{m}^{3}$

$y_{\mathrm{CO}_{2}, \text { feed }} \quad$ molar fraction of $\mathrm{CO}_{2}$ in the feed stream

\section{Greek letters}

$\varepsilon_{T} \quad$ total porosity of the bed

\section{Acknowledgements}

This work was carried out with financial support from the Spanish MICINN (Project PSE-CO2: PS-120000-2005-2; Project ENE2008-05087). M.G.P. acknowledges support from the CSIC I3P Program co-financed by the European Social Fund.

\section{References}

[1] IEA, Energy Technology Perspectives, International Energy Agency, 2008.

[2] T. Kerr, $\mathrm{CO}_{2}$ capture and storage: a global call to action, International Energy Agency, 2008.

[3] M.T. Ho, G.W. Allinson, D.E. Wiley, Reducing the Cost of $\mathrm{CO}_{2}$ Capture from Flue Gases Using Pressure Swing Adsorption, Ind. Eng. Chem. Res. 47 (2008) 4883-4890.

[4] M. Radosz, X. Hu, K. Krutkramelis, Y. Shen, Flue-Gas Carbon Capture on Carbonaceous Sorbents: Toward a Low-Cost Multifunctional Carbon Filter for "Green" Energy Producers, Ind. Eng. Chem. Res. 47 (2008) 3783-3794.

[5] S. Sjostrom, H. Krutka, Evaluation of solid sorbents as a retrofit technology for $\mathrm{CO}_{2}$ capture, Fuel 89 (2010) 1298-1306.

[6] C.A. Grande, A.E. Rodrigues, Electric Swing Adsorption for $\mathrm{CO}_{2}$ removal from flue gases, Int. J. Greenhouse Gas Control 2 (2008) 194-202.

[7] C.A. Grande, R.P.P.L. Ribeiro, A.E. Rodrigues, $\mathrm{CO}_{2}$ capture from NGCC power stations using electric swing adsorption (ESA), Energy Fuels 23 (2009) 2797-2803.

[8] M. Ishibashi, H. Ota, N. Akutsu, S. Umeda, M. Tajika, J. Izumi, A. Yasutake, T. Kabata, Y. Kageyama, Technology for removing carbon dioxide from power plant flue gas by the physical adsorption method, Energy Convers. Mgmt. 37 (1996) 929-933.

[9] E.S. Kikkinides, R.T. Yang, S.H. Cho, Concentration and recovery of carbon dioxide from flue gas by pressure swing adsorption, Ind. Eng. Chem. Res. 32 (1993) 2714-2720.

[10] J. Zhang, P.A. Webley, P. Xiao, Effect of process parameters on power requirements of vacuum swing adsorption technology for $\mathrm{CO}_{2}$ capture from flue gas, Energy Convers. Mgmt. 49 (2008) 346-356.

[11] J. Zhang, P.A. Webley, Cycle Development and Design for $\mathrm{CO}_{2}$ Capture from Flue Gas by Vacuum Swing Adsorption, Environ. Sci. Technol. 42 (2008) 563-569.

[12] J. Merel, M. Clausse, F. Meunier, Experimental investigation on $\mathrm{CO}_{2}$ postcombustion capture by indirect thermal swing adsorption using $13 \mathrm{X}$ and $5 \mathrm{~A}$ zeolites, Ind. Eng. Chem. Res. 47 (2008) 209-215.

[13] K.T. Chue, J.N. Kim, Y.J. Yoo, S.H. Cho, R.T. Yang, Comparison of Activated Carbon and Zeolite $13 \mathrm{X}$ for $\mathrm{CO}_{2}$ Recovery from Flue Gas by Pressure Swing Adsorption, Ind. Eng. Chem. Res. 34 (1995) 591-598. 
[14] W.-K. Choi, T.-I. Kwon, Y.-K. Yeo, H. Lee, H. Song, B.-K. Na, Optimal operation of the pressure swing adsorption (PSA) process for $\mathrm{CO}_{2}$ recovery, Korean J. Chem. Eng. 20 (2003) 617-623.

[15] Y. Takamura, S. Narita, J. Aoki, S. Hironaka, S. Uchida, Evaluation of dual-bed pressure swing adsorption for $\mathrm{CO}_{2}$ recovery from boiler exhaust gas, Sep. Purif. Technol. 24 (2001) 519-528.

[16] D. Ko, R. Siriwardane, L.T. Biegler, Optimization of a Pressure-Swing Adsorption Process Using Zeolite 13X for $\mathrm{CO}_{2}$ Sequestration, Ind. Eng. Chem. Res. 42 (2003) 339348.

[17] D. Ko, R. Siriwardane, L.T. Biegler, Optimization of Pressure Swing Adsorption and Fractionated Vacuum Pressure Swing Adsorption Processes for $\mathrm{CO}_{2}$ Capture, Ind. Eng. Chem. Res. 44 (2005) 8084-8094.

[18] C.-T. Chou, C.-Y. Chen, Carbon dioxide recovery by vacuum swing adsorption, Sep. Purif. Technol. 39 (2004) 51-65.

[19] N. Tlili, G. Grévillot, C. Vallières, Carbon dioxide capture and recovery by means of TSA and/or VSA, Int. J. Greenhouse Gas Control 3 (2009) 519-57.

[20] N. Konduru, P. Lindner, N.M. Assaf-Anid, Curbing the greenhouse effect by carbon dioxide adsorption with Zeolite 13X, AIChE Journal 53 (2007) 3137-3143.

[21] S. Cavenati, C.A. Grande, A.E. Rodrigues, Adsorption Equilibrium of Methane, Carbon Dioxide, and Nitrogen on Zeolite 13X at High Pressures, J. Chem. Eng. Data 49 (2004) 1095-1101.

[22] T.L.P. Dantas, S.M. Amorim, F.M.T. Luna, I.J. Silva, D.C.S. Azevedo, A.E. Rodrigues, R.F.P.M. Moreira, Adsorption of carbon dioxide onto activated carbon and nitrogen-enriched activated carbon: surface changes, equilibrium and modelng fixedbed adsorption, Sep. Purif. Technol. 45 (2010) 73-84.

[23] S. Himeno, T. Komatsu, S. Fujita, High-Pressure Adsorption Equilibria of Methane and Carbon Dioxide on Several Activated Carbons, J. Chem. Eng. Data 50 (2005) 369376.

[24] J.A. Dunne, M. Rao, S. Sircar, R.J. Gorte, A.L. Myers, Calorimetric Heats of Adsorption and Adsorption Isotherms. 2. $\mathrm{O}_{2}, \mathrm{~N}_{2}, \mathrm{Ar}, \mathrm{CO}_{2}, \mathrm{CH}_{4}, \mathrm{C}_{2} \mathrm{H}_{6}$, and $\mathrm{SF}_{6}$ on $\mathrm{NaX}$, H-ZSM-5, and Na-ZSM-5 Zeolites, Langmuir 12 (1996) 5896-5904.

[25] M.G. Plaza, C. Pevida, A. Arenillas, F. Rubiera, J.J. Pis, $\mathrm{CO}_{2}$ capture by adsorption with nitrogen enriched carbons, Fuel 86 (2007) 2204-2212.

[26] M. Plaza, C. Pevida, B. Arias, J. Fermoso, A. Arenillas, F. Rubiera, J. Pis, Application of thermogravimetric analysis to the evaluation of aminated solid sorbents for $\mathrm{CO}_{2}$ capture, J.Therm. Anal. Calorim. 92 (2008) 601-606.

[27] C. Pevida, M.G. Plaza, B. Arias, J. Fermoso, F. Rubiera, J.J. Pis, Surface modification of activated carbons for $\mathrm{CO}_{2}$ capture, Appl. Surf. Sci. 254 (2008) 71657172.

[28] M.G. Plaza, C. Pevida, B. Arias, M.D. Casal, C.F. Martín, J. Fermoso, F. Rubiera, J.J. Pis, Different approaches for the development of low-cost $\mathrm{CO}_{2}$ adsorbents, J. Environ. Eng. 135 (2009) 426-432.

[29] M.G. Plaza, C. Pevida, B. Arias, J. Fermoso, M.D. Casal, C.F. Martín, F. Rubiera, J.J. Pis, Development of low-cost biomass-based adsorbents for postcombustion $\mathrm{CO}_{2}$ capture, Fuel 88 (2009) 2442-2447.

[30] M.G. Plaza, C. Pevida, C.F. Martín, J. Fermoso, J.J. Pis, F. Rubiera, Developing almond shell-derived activated carbons as $\mathrm{CO}_{2}$ adsorbents, Sep. Purif. Technol. 71 (2010) 102-106. 
[31] Z. Liang, M. Marshall, A.L. Chaffee, CO2 Adsorption-Based Separation by Metal Organic Framework (Cu-BTC) versus Zeolite (13X), Energy Fuels 23 (2009) 27852789.

[32] D.M. Ruthven, Principles of adsorption and adsorption processes. John Wiley \& Sons: New York, 1984.

[33] D. deVault, The Theory of Chromatography, J. Am. Chem. Soc. 65 (1943) 532540.

[34] J.H. Park, H.T. Beum, J.N. Kim, S.H. Cho, Numerical Analysis on the Power Consumption of the PSA Process for Recovering $\mathrm{CO}_{2}$ from Flue Gas, Ind. Eng. Chem. Res. 41 (2002) 4122-4131.

[35] S.-H. Cho, J.-H. Park, H.-T. Beum, S.-S. Han, J.-N. Kim, J.-S.C.a.K.-W.L. SangEon Park, A 2-stage PSA process for the recovery of $\mathrm{CO}_{2}$ from flue gas and its power consumption. In Studies in Surface Science and Catalysis, Elsevier: 2004; Vol. 153, pp 405-410. 


\section{List of Tables}

Table 1. Physical properties of the adsorbent and the bed

Table 2. Operating conditions and $\mathrm{CO}_{2}$ capture capacities from the breakthrough experiments with $\mathrm{CO}_{2} / \mathrm{N}_{2}$ binary mixtures

Table 3. Operating conditions and parameters of the TSA, VSA and VTSA adsorptiondesorption cycles 
Table 1. Physical properties of the adsorbent and the bed

\begin{tabular}{cc}
\hline Adsorbent & $\mathrm{R}$ \\
BET Surface Area $\left(\mathrm{m}^{2} \mathrm{~g}^{-1}\right)$ & $942^{[27]}$ \\
Helium density $\left(\mathrm{kg} \mathrm{m}^{-3}\right)$ & 2136 \\
Apparent density $\left(\mathrm{kg} \mathrm{m}^{-3}\right)$ & 850 \\
Extrudates diameter $(\mathrm{mm})$ & 3 \\
Bed length $(\mathrm{m})$ & 0.14 \\
Bed diameter $(\mathrm{m})$ & 0.009 \\
Mass of adsorbent $(\mathrm{kg})$ & 0.004 \\
\hline
\end{tabular}


Table 2. Operating conditions and $\mathrm{CO}_{2}$ capture capacities from the breakthrough experiments with $\mathrm{CO}_{2} / \mathrm{N}_{2}$ binary mixtures

\begin{tabular}{cccccc}
\hline Case & $\begin{array}{c}\mathrm{T} \\
(\mathrm{K})\end{array}$ & $\begin{array}{c}\mathrm{P} \\
(\mathrm{kPa})\end{array}$ & $\begin{array}{c}\mathrm{Q}_{\mathrm{Feed}} \\
\left(\mathrm{cm}^{3} \mathrm{~min}^{-1} \mathrm{STP}\right)\end{array}$ & $y_{\mathrm{CO}_{2}, \text { feed }}$ & $\begin{array}{c}q_{\mathrm{CO}_{2}} \\
\left(\mathrm{~mol} \mathrm{~kg}^{-1}\right)\end{array}$ \\
\hline 1 & 303 & 130 & 34 & 0.17 & 0.77 \\
\hline 2 & 303 & 120 & 100 & 0.05 & 0.23 \\
3 & 303 & 120 & 100 & 0.09 & 0.41 \\
4 & 303 & 120 & 100 & 0.14 & 0.56 \\
\hline 5 & 313 & 120 & 100 & 0.05 & 0.21 \\
7 & 313 & 120 & 100 & 0.09 & 0.33 \\
\hline & 313 & 120 & 100 & 0.14 & 0.46 \\
\hline
\end{tabular}


Table 3. Operating conditions and parameters of the TSA, VSA and VTSA adsorption-desorption cycles

\begin{tabular}{|c|c|c|c|c|c|c|c|c|c|c|}
\hline Cycle type & $\underset{(\mathrm{t})}{\mathrm{t}_{\mathrm{c}}}$ & $\begin{array}{l}\text { Qads } \\
\left(\mathrm{cm}^{3} \mathrm{~min}^{-1} \mathrm{STP}\right)\end{array}$ & $y_{\mathrm{CO}_{2}, \text { feed }}$ & $\begin{array}{l}\mathrm{T}_{\text {ads }} \\
(\mathrm{K})\end{array}$ & $\begin{array}{c}\mathrm{P}_{\text {ads }} \\
(\mathrm{kPa})\end{array}$ & $\left(\mathrm{cm}^{3} \mathrm{~min}^{-1} \mathrm{STP}\right)$ & $\begin{array}{l}\mathrm{T}_{\text {des }} \\
(\mathrm{K})\end{array}$ & $\begin{array}{c}\mathrm{P}_{\mathrm{des}} \\
(\mathrm{kPa})\end{array}$ & $\begin{array}{c}\mathrm{CO}_{2} \text { recovery } \\
(\%)\end{array}$ & $\begin{array}{c}\text { Productivity } \\
\left(\text { mol CO }_{2} \mathrm{~kg}^{-1} \mathrm{~h}^{-1}\right)\end{array}$ \\
\hline TSA & 14 & 34 & 0.17 & 303 & 130 & 2.6 & 373 & 130 & 40 & 0.8 \\
\hline VSA & 14 & 34 & 0.17 & 303 & 130 & 0 & 303 & 0.005 & 87 & 1.7 \\
\hline VTSA & 14 & 34 & 0.17 & 303 & 130 & 0 & 323 & 0.005 & 97 & 1.9 \\
\hline
\end{tabular}




\section{List of Figures}

Figure 1. Scheme of the fixed-bed adsorption unit.

Figure 2. Graphical method to estimate the capture ratio $A_{t} / A_{\text {tot }}$.

Figure 3. (a) $\mathrm{CO}_{2}$ and $\mathrm{N}_{2}$ adsorption isotherms at $303 \mathrm{~K}$, (b) $\mathrm{CO}_{2} / \mathrm{N}_{2}$ selectivity.

Figure 4. $\mathrm{CO}_{2}$ adsorption isotherms at $298 \mathrm{~K}$ up to $3 \mathrm{MPa}$ for zeolite $13 \mathrm{X}$ [21] and carbon R.

Figure 5. Breakthrough experiments at $303 \mathrm{~K}$ and $130 \mathrm{kPa} \quad\left(y_{\mathrm{CO}_{2}, \text { feed }}=0.17\right.$, $\mathrm{Q}=34 \mathrm{~cm}^{3} \min ^{-1} \mathrm{STP}$ ): (a) complete experiment consisting of 10 consecutive adsorption-desorption cycles, (b) detail of a single cycle, and (c) consecutive breakthrough curves.

Figure 6. $\mathrm{CO}_{2}$ breakthrough curves (Cases 2-7 in Table 2; $\mathrm{Q}=100 \mathrm{~cm}^{3} \min ^{-1} \mathrm{STP}$, $\mathrm{P}=120 \mathrm{kPa})$.

Figure 7. TSA cycles: a) schematic representation of the cycle configuration, and b) evolution of the $\mathrm{CO}_{2}$ molar fraction at the bed outlet (x), and bed temperature history (一) along the experiment.

Figure 8. VSA cycles: a) schematic representation of the cycle configuration, and b) evolution of the $\mathrm{CO}_{2}$ molar fraction in the effluent stream (x), and bed pressure history (---) along the experiment.

Figure 9. VTSA cycles: a) schematic representation of the cycle configuration, and b) evolution of the $\mathrm{CO}_{2}$ molar fraction in the effluent stream (x), bed pressure (---), and temperature (-) histories along the experiment.

Figure 10. Comparison of the working capacities of the TSA, VSA and VTSA adsorption-desorption cycles carried out. 

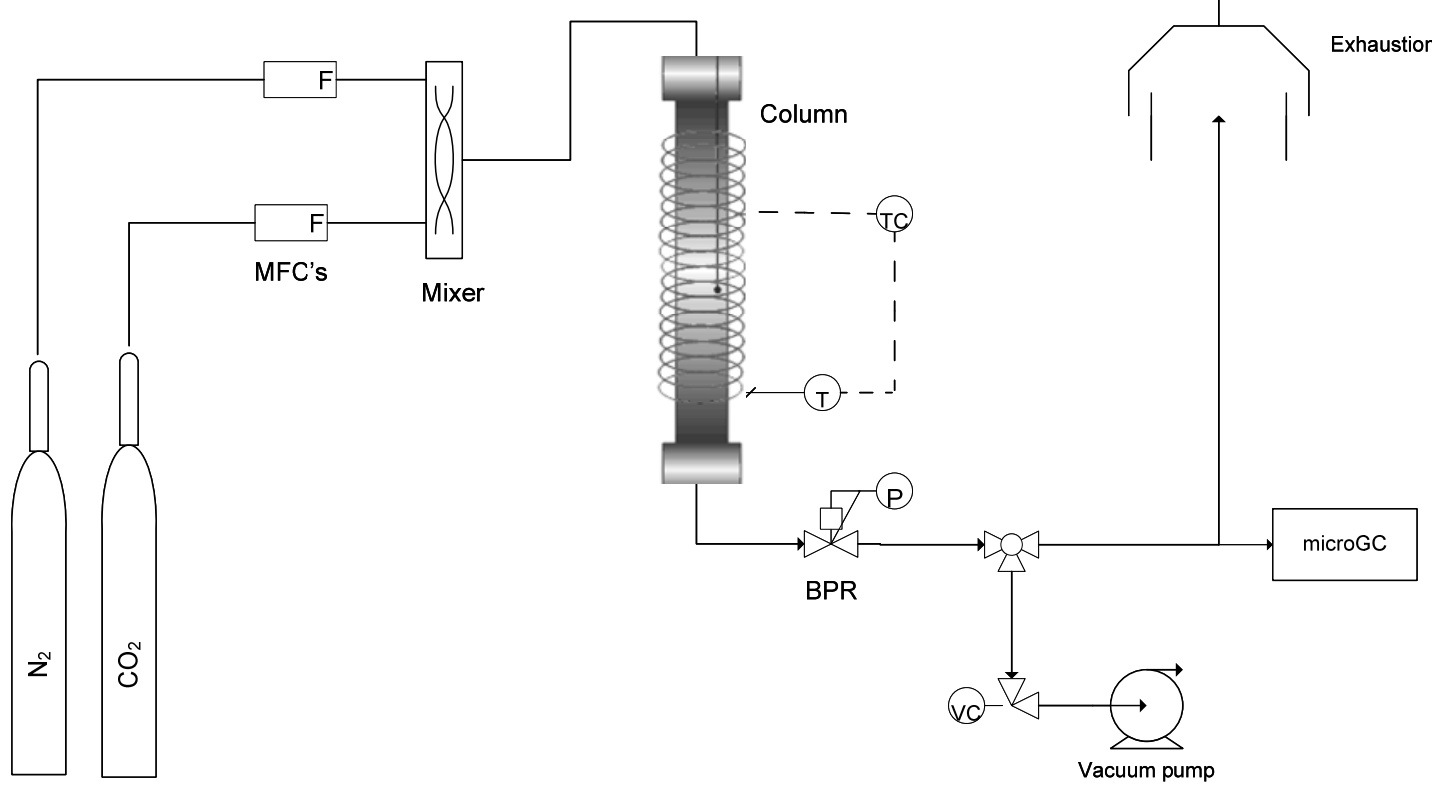

Figure 1. Scheme of the fixed-bed adsorption unit. 


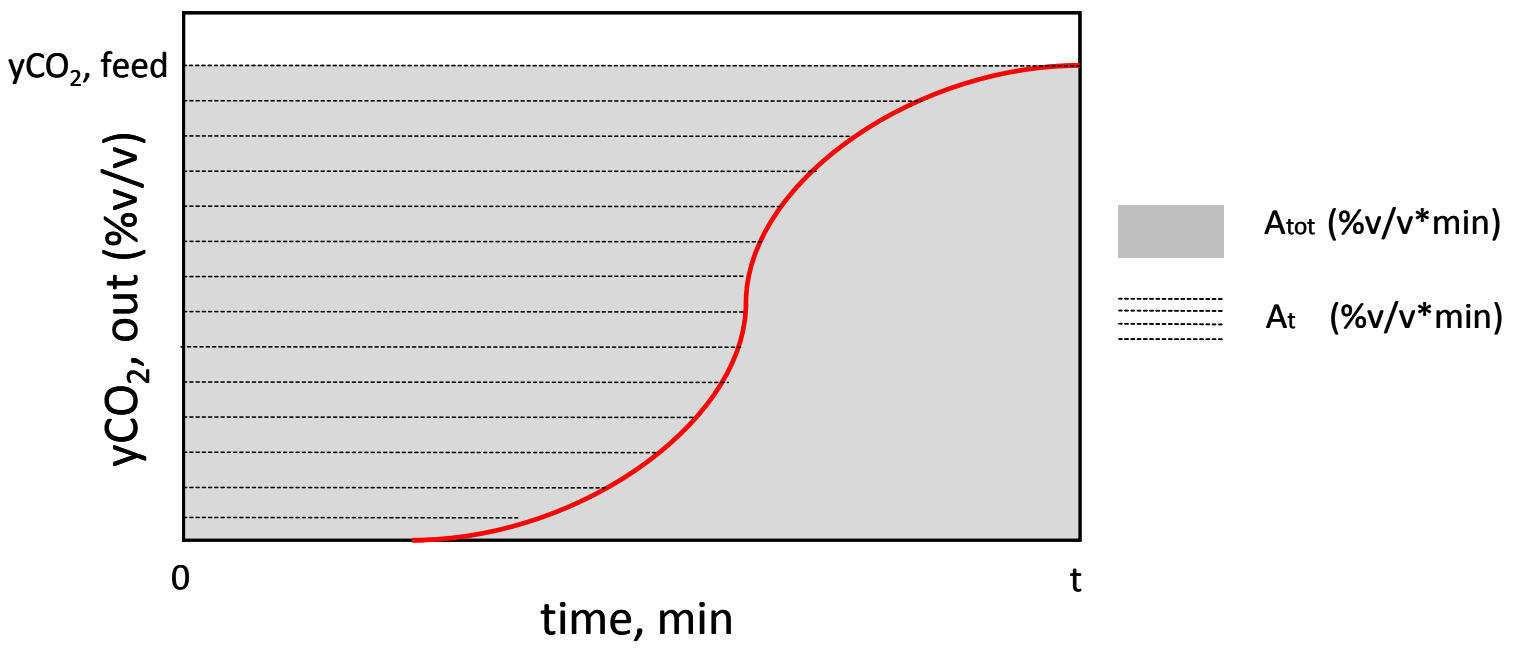

Figure 2. Graphical method to estimate the capture ratio $A_{t} / A_{t o t}$. 

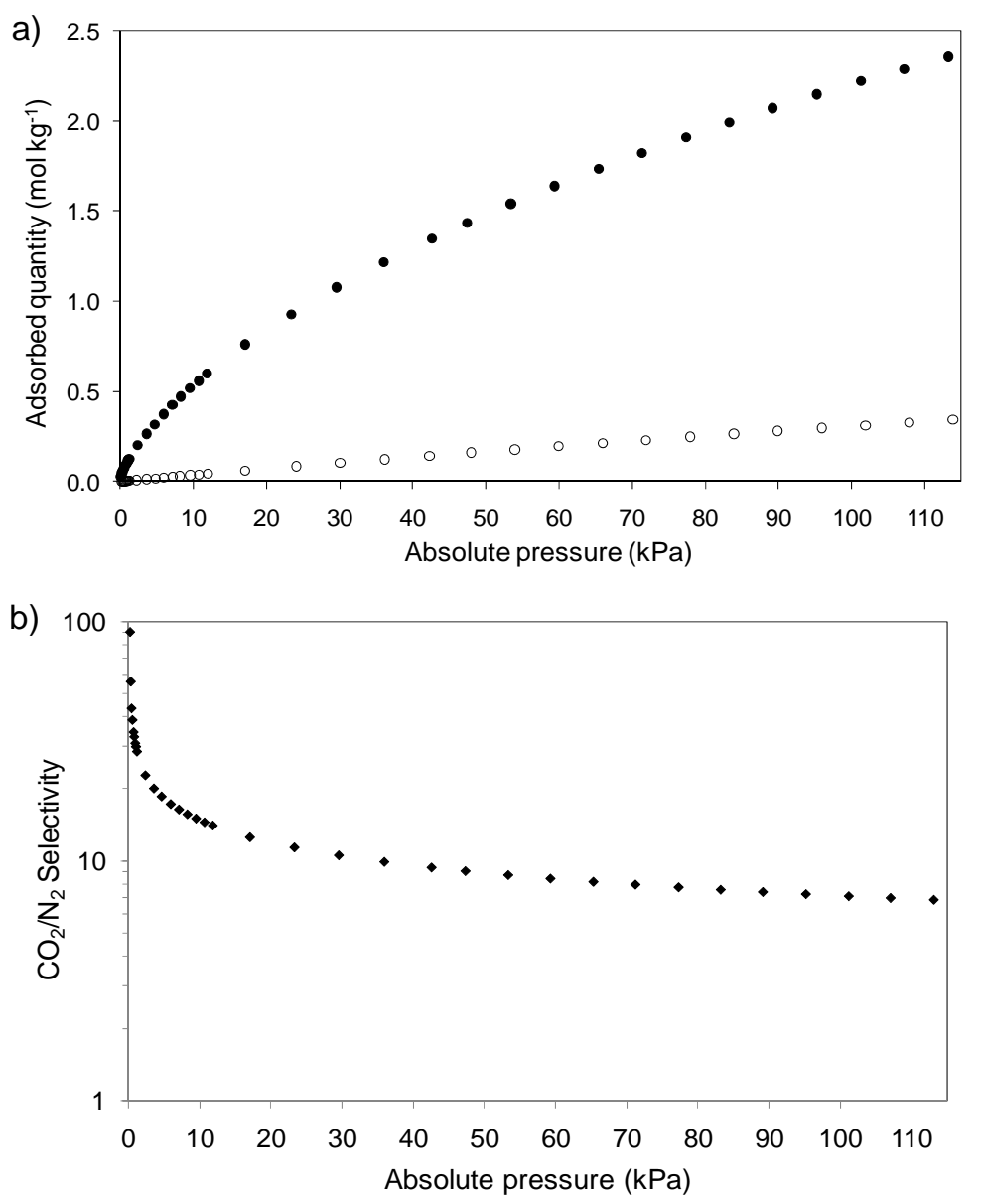

Figure 3. (a) $\mathrm{CO}_{2}$ and $\mathrm{N}_{2}$ adsorption isotherms at $303 \mathrm{~K}$, (b) $\mathrm{CO}_{2} / \mathrm{N}_{2}$ selectivity. 


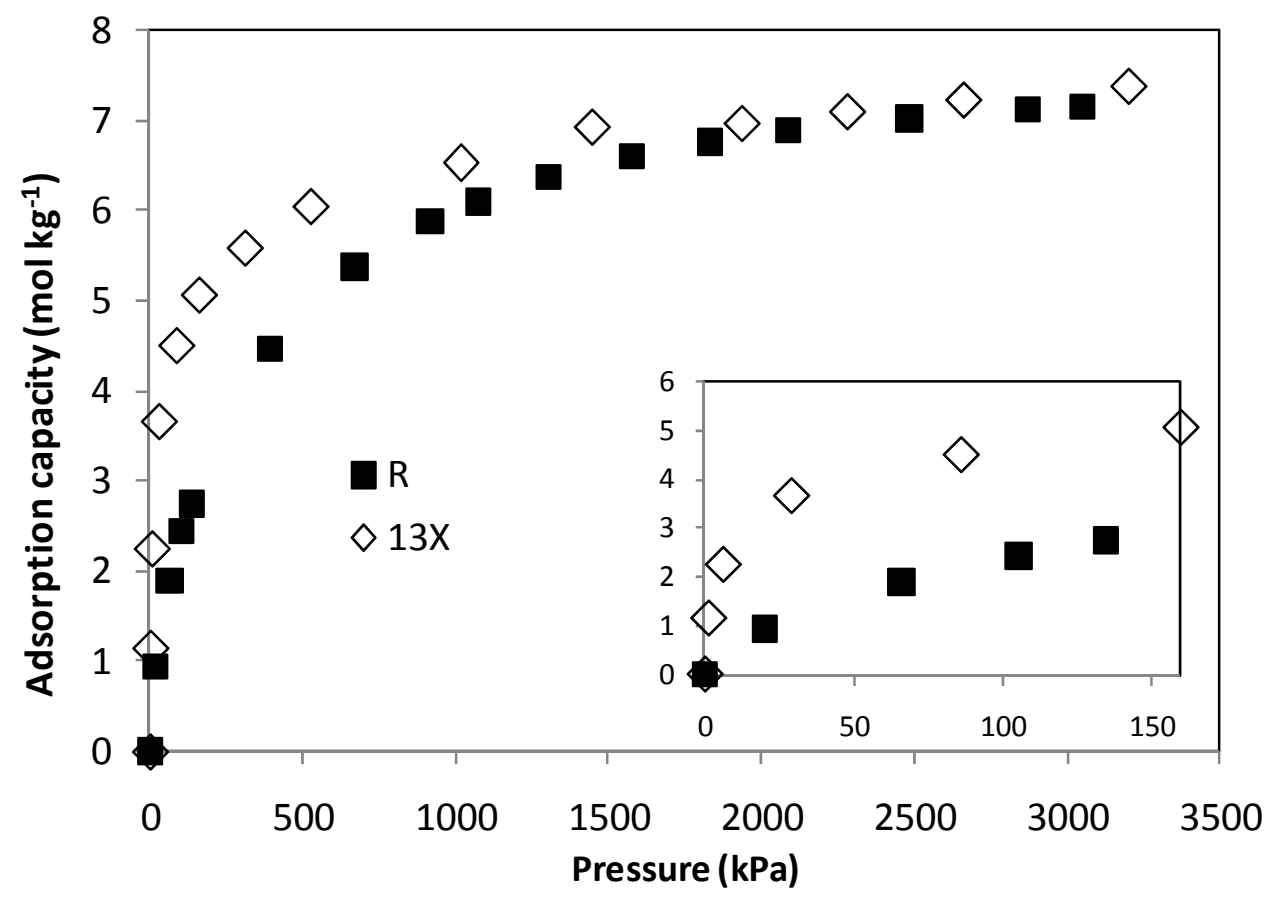

Figure 4. $\mathrm{CO}_{2}$ adsorption isotherms at $298 \mathrm{~K}$ up to $3 \mathrm{MPa}$ for zeolite $13 \mathrm{X}$ [21] and carbon $\mathrm{R}$. 

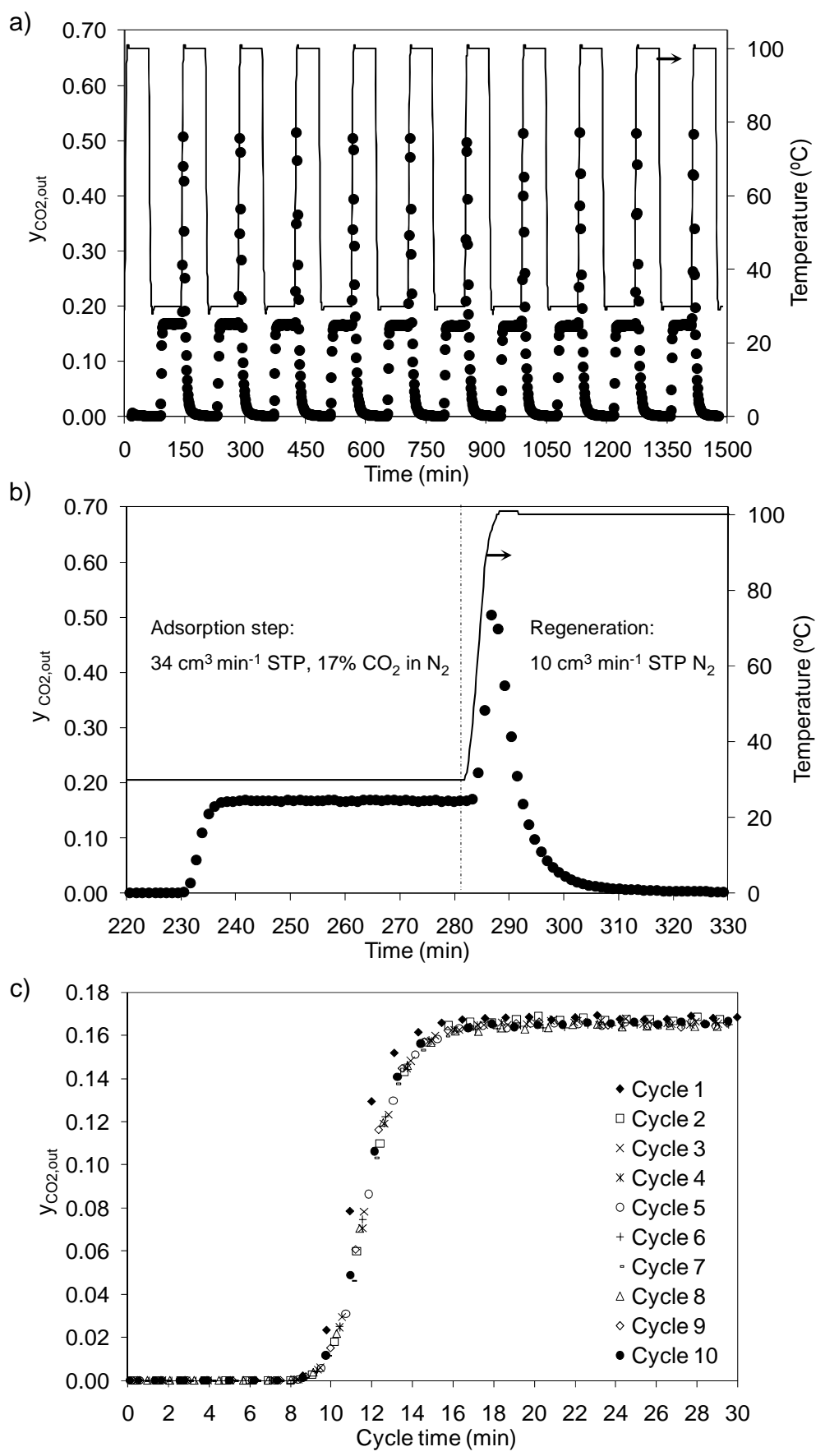

Figure 5. Breakthrough experiments at $303 \mathrm{~K}$ and $130 \mathrm{kPa} \quad\left(y_{\mathrm{CO}_{2} \text {, feed }}=0.17\right.$, $\mathrm{Q}=34 \mathrm{~cm}^{3} \mathrm{~min}^{-1} \mathrm{STP}$ ): (a) complete experiment consisting of 10 consecutive adsorption-desorption cycles, (b) detail of a single cycle, and (c) consecutive breakthrough curves. 


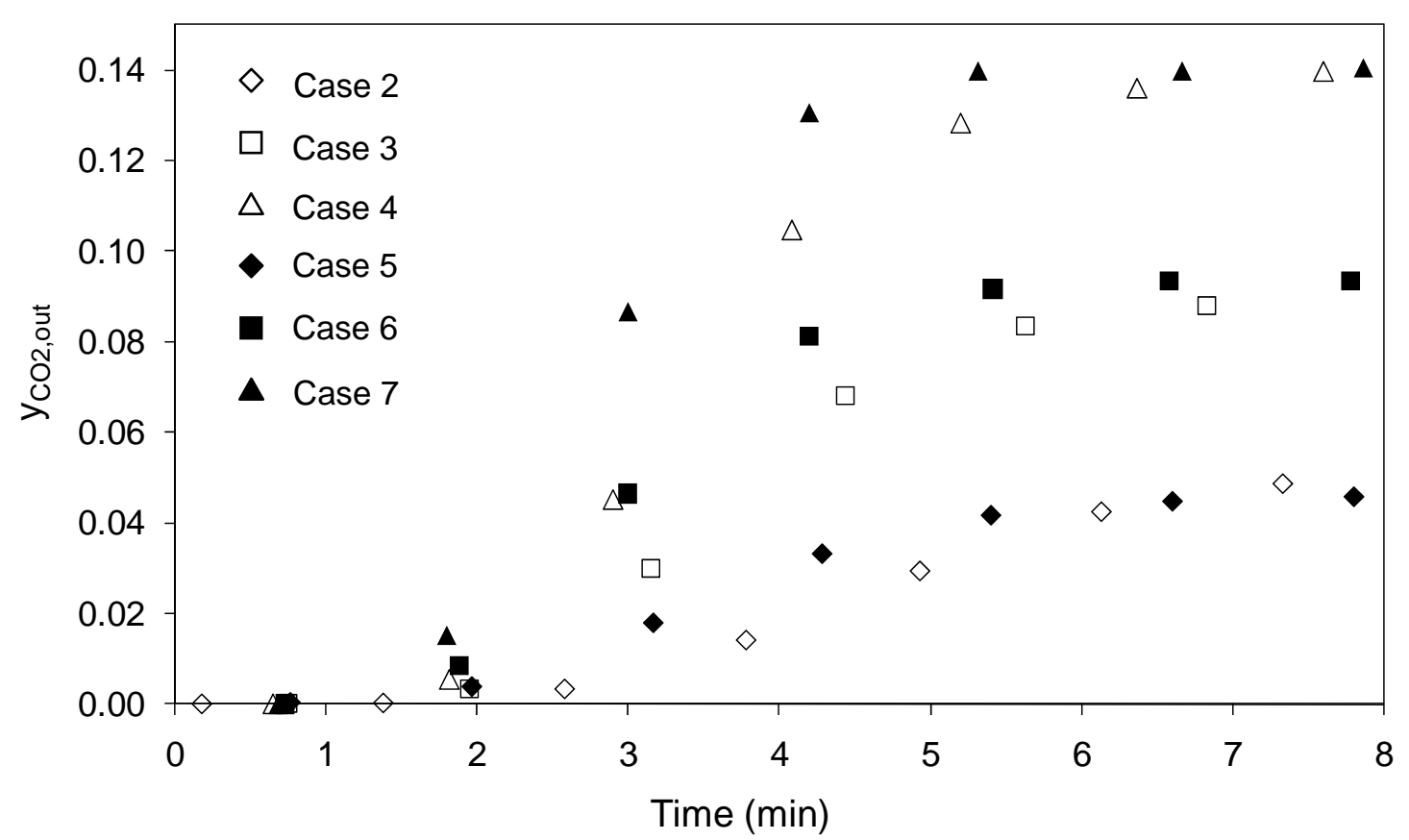

Figure 6. $\mathrm{CO}_{2}$ breakthrough curves (Cases 2-7 in Table 2; $\mathrm{Q}=100 \mathrm{~cm}^{3} \mathrm{~min}^{-1} \mathrm{STP}$, $\mathrm{P}=120 \mathrm{kPa})$. 

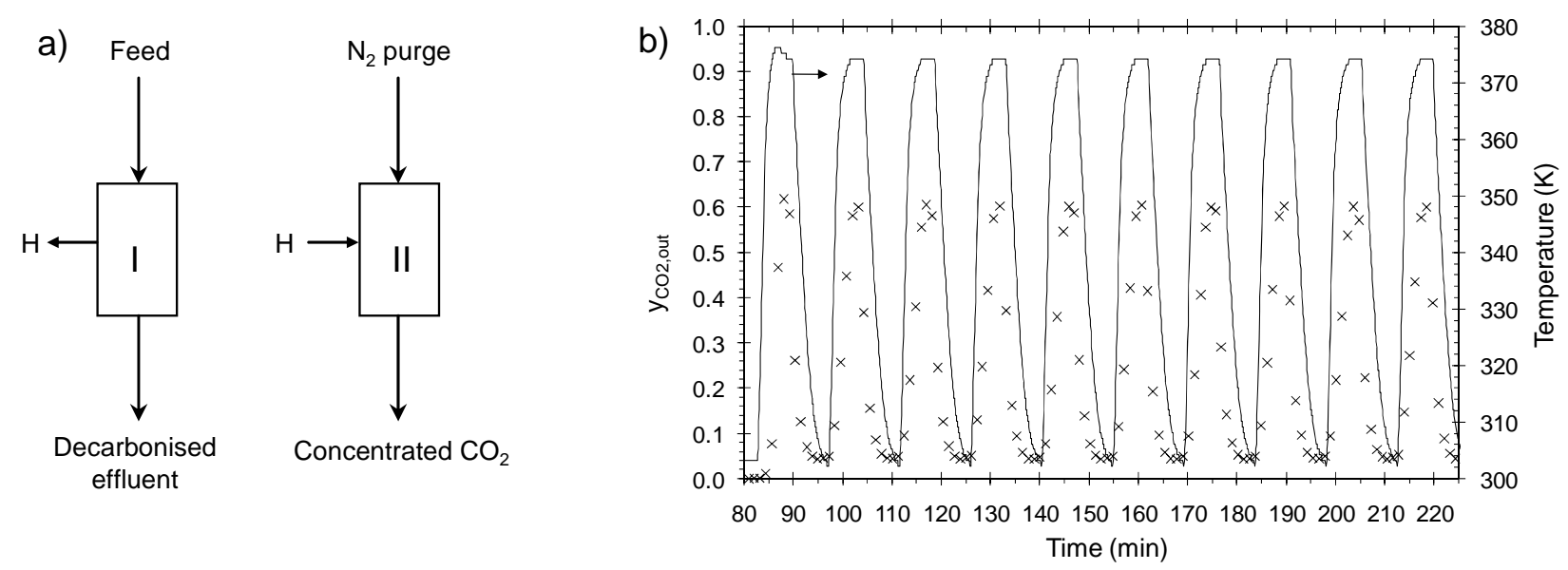

Figure 7. TSA cycles: a) schematic representation of the cycle configuration, and b) evolution of the $\mathrm{CO}_{2}$ molar fraction at the bed outlet (x), and bed temperature history (一) along the experiment. 
a)

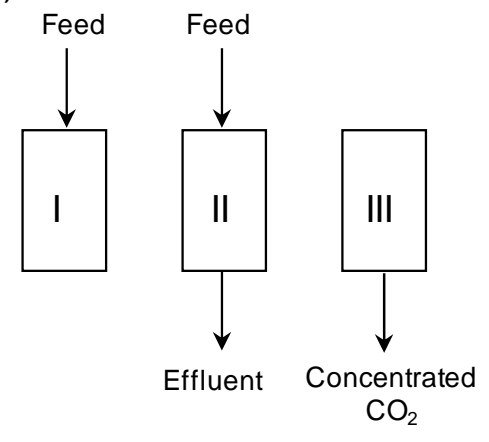

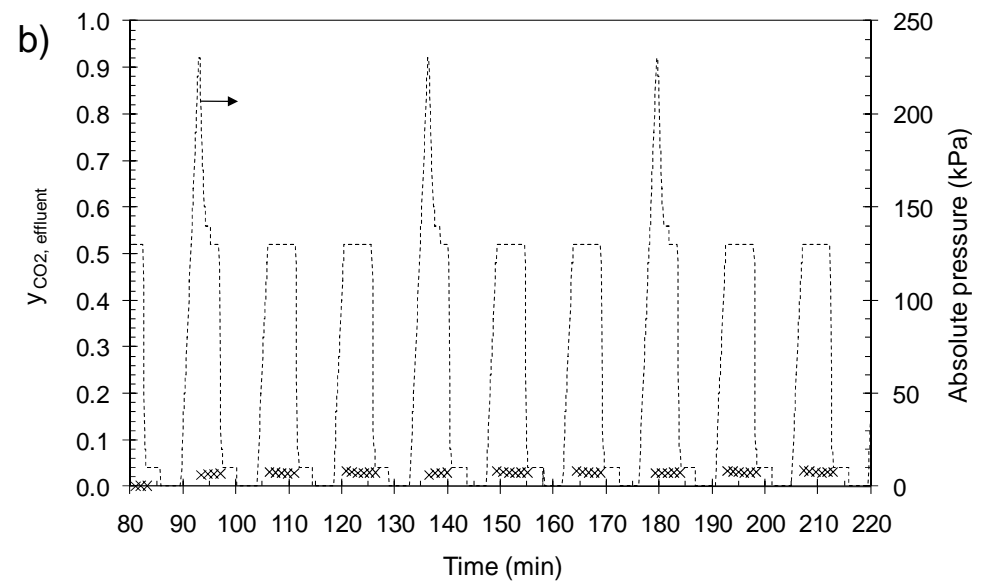

Figure 8. VSA cycles: a) schematic representation of the cycle configuration, and b) evolution of the $\mathrm{CO}_{2}$ molar fraction in the effluent stream (x), and bed pressure history (---) along the experiment. 
a)

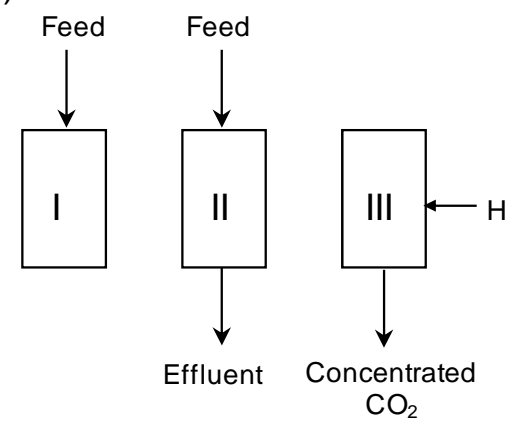

b)

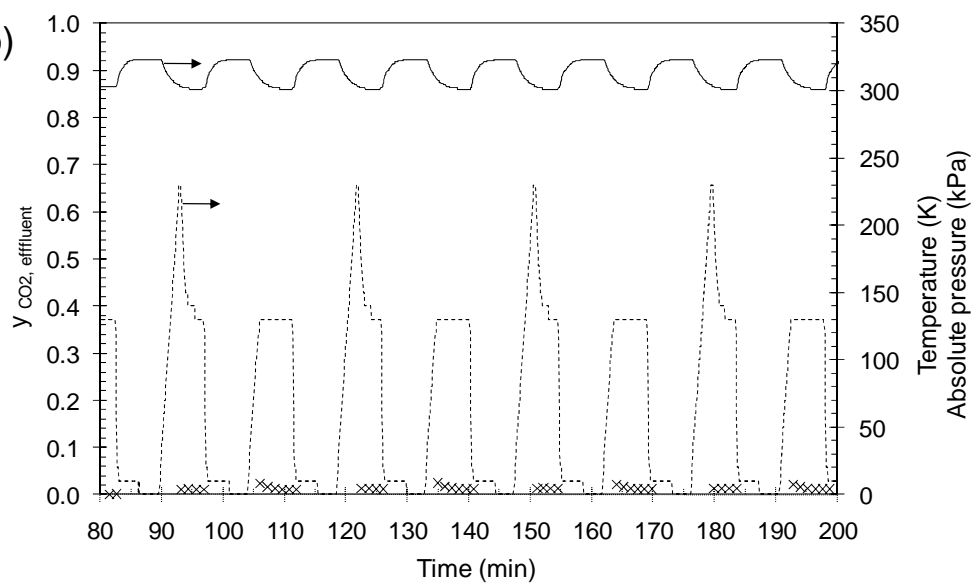

Figure 9. VTSA cycles: a) schematic representation of the cycle configuration, and b) evolution of the $\mathrm{CO}_{2}$ molar fraction in the effluent stream (x), bed pressure (---), and temperature (-) histories along the experiment. 


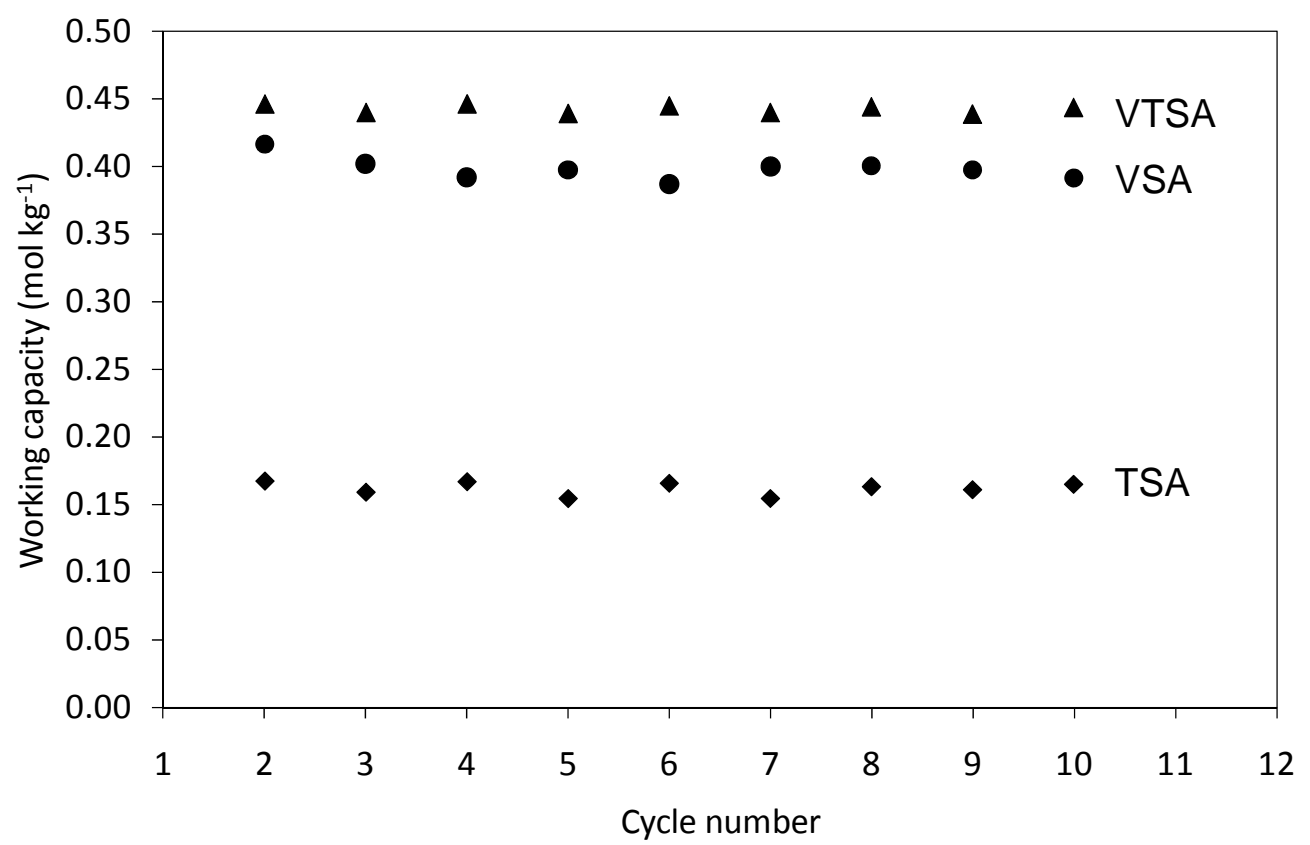

Figure 10. Comparison of the working capacities of the TSA, VSA and VTSA adsorption-desorption cycles carried out. 